\title{
A Study of English Film Title Translation —From the Perspective of Adaptation Theory
}

\author{
LI Qi \\ School of Foreign Languages, Jinan University, Guangzhou City, China
}

\begin{abstract}
As the exchange between Chinese and Western cultures gets increasingly frequent, the English films have already become an indispensable kind of cultural "product" in Chinese people’s lives. In the pursuit of box office today, a good English film title translation can not only attract more attention, but also become an important standard to judge a film's value. However, the translation of English film title has not got enough attention at home or abroad, and good translations of English film titles are few and far between. Based on requirements of English film title translation, this paper discusses problems in English film title translation, into which this paper applies adaptation theory to solving existing problems.
\end{abstract}

Keywords: adaptation theory, English film title, culture, Chinese translation

\section{Introduction}

With the continuous development of international cultural exchanges, an increasing number of English films are introduced into China, causing a growing demand of translations of English films. Film, as an important cultural medium, is increasingly drawing worldwide attention, acting as a window to catch a glimpse of foreign culture. Film title translation is not only a form of artistic expression, reflecting the filmmaker's artistic creativity, but also helps improve aesthetic ability among the audience. Meanwhile, it also has a pragmatic commercial value, playing a vital role in the promotion of films.

However, in English film title translation, due to a lack of cultural background knowledge, only a few good renderings are produced. Most English film title translations are mistranslations. Therefore, those bad translations make audience have difficulty in understanding films and fail to attract them to watch films.

This paper aims to improve the quality of English film title translation and maximize the commercial value of English films. Based on adaptation theory, this paper takes culture into consideration to help the translations of English film titles get more acceptable by Chinese audience and help translators and translation learners better understand differences between Chinese and English languages.

\section{An Overview of Adaptation Theory}

Adaptation Theory is a linguistic theory, proposed by a Belgian linguist, Jef Verschueren. In his view, language use is a process of language function; or rather language user continues to vary their language means as communicative situation varies, to achieve the communicative goal.

According to Verschueren, language use is a process of making choices "Using language must consist of

LI Qi, Master of Arts, School of Foreign Languages, Jinan University. 
the continuous making of linguistic choices, consciously or unconsciously, for language-internal (i.e. structural) and/or language-external reasons" (Verschueren, 2000, p. 55). Jef Verschueren proposes a pragmatic perspective on language use and assumes language use to be continuous linguistic choice-makings with different degrees of salience for the purpose of adaptation. Adaptation Theory has some following characteristics.

(1) Choice-making. Verschueren views the process of using language as making choices. He points out "whether for language-internal (i.e. structural) and/or language-external reasons, using language must consist of the continuous linguistic choices, consciously or unconsciously". At any level of linguistic areas these choices can be made, whether it is phonetic, phonological, morphological, lexical, syntactic, or semantic level. Just like all verbal communication activities, translation involves continuous choice-making (SONG, 2004, p. 20).

(2) Three properties of language. Language has three inter-related properties, namely, variability, negotiability and adaptability. These three inter-related properties of language explain why human beings can make choices in the process of language use. Among them, adaptability is at the core of language use. Variability is "the property of language which defines the range of possibilities from which choices can be made” (Verschueren, 2000, p. 59). Language selection range keeps changing, that is, some old expression may rarely be employed or no longer be employed again, but at the same time, new expressions keep coming into being. Negotiability is "the property of language responsible for the fact that choices are not made mechanically or according to strict rules or fixed form-function relationships, but rather on the basis of highly flexible principles and strategies" (Verschueren, 2000, p. 59). Adaptability is the property of language which enables human beings to make negotiable linguistic choices from a variable range of possibilities in such a way as to approach points of satisfaction for communicative needs (Verschueren, 2000, p. 69).

(3) Four angles of investigation. Contextual correlates of adaptability, structural objects of adaptability, dynamics of adaptability, and salience of the adaptation process are known as four angles. Firstly, Verschueren explains that contextual correlates of adaptability potentially include all the ingredients of the communicative context, with which linguistic choices have to be inter-adaptable (Verschueren, 2000, p. 66). The range goes from aspects of the physical surroundings (e.g. distance as an influence on loudness of voice) to social relationships between speakers and hearers, and aspects of the interlocutors' state of mind. Therefore, linguistic adaptation could be examined from four interrelated angles for a better pragmatic description and explanation. Secondly, Verschueren states that since the making of communicative choices takes place at all possible levels of linguistic structure that involve variability of any kind, pragmatic phenomena can be related to any layer or level of structure, from sound feature and phoneme to discourse and beyond, or to any type inter-level relationship (Verschueren, 2000, p. 66). Thus structural objects of adaptability not only refer to "structures", but also involve principles of "structuring". Thirdly, according to Verschueren, dynamics of adaptability is the key angle in the adaptation theory. That is, "the ways in which communication principles and strategies are used in the making and negotiating of choices of production and interpretation" (Verschueren, 2000, p. 66). Fourthly, salience of the adaptation process refers to the status of process of meaning generation in relation to the cognitive apparatus. Verschueren explains "not all choices, whether in production or interpretation, are made equally consciously or purposefully" (Verschueren, 2000, p. 66). These four angles are in perfect agreement with the linguistic, social, cultural and cognitive elements involved in the dynamic process of language use. 


\section{Requirements of English Film Title Translation}

\section{Requirement of True Reflection of English Film Content}

The basic function of English film title is to summarize English film content. The information about English films with which the audience first come into contact is their titles. It can also be regarded as the synopsis of the whole English film. For those translators who adopt the character name or the name of the place where the story is set, it is easy to meet this requirement, such as the Chinese translations of English films The Hunger Games into 饥饿游戏, Ant-Man into 蚁人, Batman vs. Superman: Dawn of Justice into 蝙蝠侠大战 超人: 正义黎明 etc. This kind of Chinese translation can immediately convey the main information to the audience and arouse the audience's curiosity and attention.

However, as far as other English films titles are concerned, to reflect the content of the English film means that in the process of translation of the English film title, based on the full understanding of the English film, the translator should change the original English film title slightly, or even abandon the original one and substitute it for another. Otherwise, the mechanical translation of the original will make the audience feel baffled. For example, the English film Inception is translated into 䀆梦空间 instead of 开始, The Revenant is translated into 荒野猎人 rather than 亡魂, Big Hero 6 translated into 超能陆战队 rather than 六个大英雄 etc. Compared with the former version known as mechanical translation, the latter adds the main plot and better summarizes the main contents of English film.

\section{Requirement of Brevity and Sonority}

The intended addressee of English film is the general public. This feature determines that the language of English film titles should be easy to understand and orally catchy, since the audiences are from all walks of life, different ages, different occupations, and different education backgrounds. Popular language is usually adopted in English film title translation, for it is easy to be understood. Moreover, vivid and attractive language is the best tool to entertain the audience with a sense of beauty. Linguistically speaking, noun phrases, gerunds as well as diverse rhetorical devices are usually employed by the majority of English film titles, however, verbs or verb phrases are less often used. In the meantime, some decorative words such as adjectives are frequently applied to make the English film title more dramatic and intriguing.

\section{Requirement of Reflecting Culture}

Cultural elements are considered to be one of the most difficult translation tasks. There are so many ways to reflect the cultural connotation, such as cultural legendary, idioms, and so on. for example, the "First Blood" is an idiom, meaning wining the first battle, but it has been translated into 第一滴血. The film A Space Odyssey contains cultural background, where Odyssey means a dangerous journey. If the film is directly transliterated into “奥德赛”, it will make non-English learners feel confused.

\section{Problems in English Film Title Translation}

\section{Mechanical Translation}

Mechanical translation only preserves language form of source language, losing the exact meaning of the source language. Different from mechanical translation, literal translation preserves language form of the source language, conveys the exact meaning of the source language and becomes acceptable by target language users. Mechanical translation and literal translation both preserve language of source language, but mechanical translation cannot express the exact meaning of source language. For example, Hobson's Choice, an English 
film, won the Golden Bear at the 4th Berlin International Film Festival in 1954. It was translated mechanically into 霍布森的选择 in Mainland and Taiwan but it was translated freely into 女大不中留 (an apparently free choice that offers no real alternative) in Hong Kong. The first translated version is just mechanical translation of the original English film title. However, it conveys the wrong meaning to Chinese audience for there is no real free choice in the film. Actually, according to American Heritage Dictionary, "Hobson's Choice" means “an apparently free choice that offers no real alternative”. Therefore, the free version 女大不中留 (an apparently free choice that offers no real alternative) represents source culture in a better way and manifests well the cultural connotation of this idiom and made itself comprehensible to the Chinese audience.

\section{Cultural Misunderstanding}

Language is the product of society and culture. For the same object like animal, color or occupation, people from different cultures may have different cultural understanding. For example, "dragon" is a derogatory term in the West. We can see from the example of Satan in Bible where the greatest evil, Satan, once presented himself as a dragon with seven heads, devouring new-born children viciously. Since then, the dragon has become a symbol of evil. Many literature works use dragon as the biggest villain, the biggest rival of knights who are generally regarded as heroes in westerners' minds. It is the frequently-used happy ending that knights kill the cruel dragon to save princess's life. While in ancient Chinese legend, "dragon" is a commendatory term, auspicious mascot to bring rainfall and drive away evils. Chinese adore and worship dragon and they are proud of calling themselves as descendants of dragon (龙的传人). Dragon also represents royalty. Chinese emperors have their clothes embroidered with dragon to show their dignity, while common people are forbidden to use dragon as their symbol. It is the different cultures that cause different connotative meanings of the same object. Therefore, the English film Dragon Heart is preferably translated into 魔龙传奇 than literally translated into 龙之心 because the dragon in the English film is brutal, ruthless and claims a large number of souls. However, the dragon in Chinese culture stands for royalty, power and auspicious omen. The version of 龙之心 will mislead Chinese audience to deem the dragon as a positive character.

\section{Strategies of English Film Title Translation Based on Adaptation Theory}

\section{Adaptation to Speech Sounds}

Vershueren explains that language use is a process of the continuous linguistic choices. This view holds true for translation, because in essence translation is an actual practice of language use. Put it more straightforwardly, translation is a process involving continuous choice-making. According to SONG, choice-making occurs during the whole translation process and he also maintains choice-making involves not only the choice of the text to be translated, the adoption of translation strategy, but also the choice of meaning potentials when analyzing the text (SONG, 2004). In the translation of English film titles, translators can use alliteration, assonance and palindrome to make English film titles orally catchy and melodious to ears. Some devices also are of great help in the expression of the emotion meaning and the enhancement of the beauty of music. For example, the Chinese translation of American film Speed into 生死时速, every word has a sound of $\mathrm{S}$ as the initial consonant, greatly adapting to the phonologically aesthetic feeling and artistic appeal.

Balanced structure is orally catchy, for example, Mission: Impossible is translated into 碟中碟, The Sting is translated into 骗中骗, Charade is translated into 迷中迷, as well as Dumb Dumber is translated into 阿呆 与阿瓜. The above examples of translation not only adapt to speech sounds, but adapt to the aesthetic mind of 
Chinese audience. They are clever, succinct, fully demonstrating the Chinese culture and artistic charm. Moreover, by adapting to speech sounds, we can successfully bridge the distance between the English films and audience. Therefore, the audience is attracted unconsciously and the commercial value of English film is increased.

\section{Adaptation to Four-Character Idioms}

Chinese language culture with extensive and profound history is the accumulation of long-term social and cultural life of Chinese nation. Four-character idioms have been considered as the essence of the Chinese language and culture. According to Fang Mengzhi, four-character idioms are terse and symmetry in structure, deep and thought-provoking in meaning and powerful in emotion expression. If four-character idioms are used properly in English film translation, they will not only convey the English film information, but also can fully adapt to the Chinese audience's aesthetic minds. There are too many examples, just name a few, the Chinese translations of The Untouchables into 铁面无私, The Thomas Crown Affair into 天罗地网, How Green Was My Valley into 青山翠谷, Dance With Wolves into 与狼共舞, Frozen into 冰雪奇缘. They all adapt to four-character idioms.

In some cases, there are many cultural elements in English film titles which are completely strange to Chinese audiences and pose a challenge to their understanding. These English cultural elements usually include religious connotation, idioms or slang and may lead to misunderstanding or confusion of Chinese audiences. In Chinese translation of such English film titles, creation is needed. Creation sometimes is needed in the Chinese translation of English film titles. In this way, we can adapt English film titles to the cultural mind of Chinese audiences by using four-character idioms. There are a few examples, like the Chinese translations of The Wizard Of Oz into 绿野仙踪, Blood And Sand into 碧血黄沙.

\section{Adaptation to Poetry}

Chinese people prefer to be aesthetically reserved which can be found full expression in the classical Chinese literature. After an analysis of a large number of English film title translations, it is easy to see that many English film title translations are profoundly influenced by poetry, which adapts to the Chinese traditional literary work. There is an excellent example to illustrate this point, the English film Blossom In The Dust is translated into 落花飘零. “落花飘零” comes from the Li Qingzhao’s famous poem, “flowers from wandering water gravity, a kind of acacia, two place idle sorrow, has a parting thoughts and acacia flowers fall to the ground (花自飘零水自流，一种相思，两处闲愁)”. This translation applies the melancholic expression “落花飘零” into the English film title translation, presenting a image of one sad mother lamenting her dead child. The connotation of the film and classical poetry are perfectly combined together, making the film harmonious in content and creating poetic image beauty. It is a wonderful example of adapting to classical Chinese poetry.

\section{Adaptation to Culture}

Chinese audiences are doing a kind of cross-cultural communication when they watch English films. English film plays an important part in such communication. XU discusses the importance of cross-cultural adaptation in cross-cultural and he suggests that the communication between different countries should adapt to cultures. Translation serves as a bridge between different cultures (2004, p. 362).

Many English idioms are derived from legendary stories or Bible. It is the same case with some English film titles. For example, an old film named Salt of the Earth, is about the life and struggle of American workers 
in the 1940s. The mechanical translation of “地球的盐” may misdirect the audiences to regard this film as a technological film, thus the cultural connotation is lost. Based on the understanding of this English idiom, this title should be translated into “社会中坚” in Chinese. “Salt of the earth” is from the New Testament. Salt has been precious and important since ancient times. Jesus compares his disciples as "salt of the earth" to show his high praise. And now, in English, "salt of the earth” is an idiom referring to elites in the society. Therefore, “社 会中坚” can better express the hidden meaning of the idiom, which means the backbone of society. More importantly, “社会中坚” can correctly convey the right information about the film. If the translator is not familiar with the cultural background, he can hardly get the exact information properly translated. In terms of the English film title translation, it is of much importance to have a good understanding of cultural background.

\section{Conclusion}

This paper has discussed the application of the adaptation theory to the translation of English film titles. Due to the cross-cultural differences between Chinese and English, the absolute equivalence does not exist. Therefore, translators should bear translation requirements of English film titles in mind and produce more appropriate Chinese translations of English film titles based on adaptation theory.

\section{References}

SONG, Z. P. (2004). Translation: Choice and adaptation—Translation study from the perspective of adaptation theory. Chinese Translators Journal, 25(2), 19-23.

Verschueren, J. (2000). Understanding pragmatics. Beijing: Beijing Foreign Language Teaching and Research Press. XU, L. S. (2004). Intercultural communication. Shanghai: Shanghai Foreign Language Education Press. 